\title{
Overall and Gender-specific Associations between C-reactive Protein and Stroke Occurrence: A Cross-sectional Study in US
}

\author{
Yang Peng, Bin Dong, Zhiqiang Wang \\ Centre for Chronic Disease, School of Medicine, University of Queensland, Herston, Australia
}

\section{Dear Sir:}

C-reactive protein (CRP), a marker of systemic inflammation, has been proposed to increase the risk of stroke, a common cardiovascular disease, in multiple cross-sectional and prospective studies. ${ }^{12}$ While, a few reports found CRP had no apparent value for stroke predictions. ${ }^{3}$ Furthermore, the gender-specific associations between CRP concentration and stroke occurrence are not well clarified. We used data collected from the National Health and Nutrition Examination Survey (NHANES), a large representative US national dataset, to testify the overall and gender-specific associations between CRP level and stroke prevalence.

NHANES has a complex multistage sample design to provide a nationally representative sample of the non-institutionalized US general population. We conducted our study based on the public-access data of adults aged 20 years or older from 1999-2010 NHANES dataset. All participants provided written informed consent and the National Center for Health Statistics Research Ethics Review Board approved all protocols. The subjects were considered to have stroke if they answered "yes" to the question "Has a doctor or other profession ever told you have a stroke?". Those with answer of "don't know" or incomplete answers were excluded from our study. The subjects were categorized into high CRP group (CRP $>3 \mathrm{mg} / \mathrm{L}$ ) and normal CRP group (CRP $\leq 3 \mathrm{mg} /$ L). Age, race/ethnicity, body mass index, low-density lipoprotein cholesterol, diabetes and smoking status were included as covariates in our study, and they were adjusted in multivariate models because they are regarded as traditional stroke risk fac- tors. Data are summarized as mean (standard deviation) or median (interquartile range) in the case of continuous variables and as percentages in the case of categorical variables. Logistic regression analyses were used to explore the relationship of higher CRP concentration and the strengths of the association were estimated by odds ratios along with their corresponding 95\% confidential intervals (Cls). In addition, population attributable fractions were computed to determine the proportion of stroke occurrence attributable to higher CRP level. All analyses were performed by Stata software, version 14.1 (Stata Corp, College Station, TX). All tests were 2 tailed, and a $P$ value $<0.05$ was considered statistically significant.

A total of 32,408 participants were enrolled in our study, including 15,495 men and 16,913 women. The overall prevalence of stroke is $4.0 \%(1,284 / 32,408)$. Baseline characteristics of the participants are presented in Table 1. According to the multivariate logistic analysis, higher CRP concentration is related to greater odds of stroke in the overall population (odds ratio $=1.38 ; 95 \% \mathrm{Cl}: 1.11-1.71 ; P=0.004)$. Multivariate analyses stratified by gender revealed a non-significant association between higher CRP level and stroke in males (odds ratio $=1.32$; 95\% Cl: 0.97-1.79; $P=0.079$ ). While, the association remained significant in females (odds ratio $=1.42 ; 95 \% \mathrm{Cl}$ : 1.04-1.94; $P=0.026$ ). In the overall population, $13 \%$ of stroke was attributable to higher CRP concentration (95\% Cl: 0.04-0.21). However, the population attributable risk of elevated CRP for stroke was not significant in male, with population attributable fractions of 10\% (95\% Cl: -0.02-0.20). Removal of higher CRP level was 
Table 1. Basic characteristics of participants.

\begin{tabular}{|c|c|c|c|}
\hline Factors & $\begin{array}{c}\text { Males } \\
(n=15,495)\end{array}$ & $\begin{array}{c}\text { Females } \\
(n=16,913)\end{array}$ & $\begin{array}{c}\text { Total } \\
(n=32,408)\end{array}$ \\
\hline Stroke (\%) & 4.1 & 3.8 & 4.0 \\
\hline $\begin{array}{l}\text { C-reactive protein (CRP), mg/L } \\
\text { [median (IOR)] }\end{array}$ & $1.7(3.1)$ & $2.8(5.2)$ & $2.2(4.2)$ \\
\hline $\begin{array}{l}\text { Age, year [median } \\
\text { (IQR)] }\end{array}$ & $50.0(31.0)$ & $48.0(32.0)$ & 49.0 (31.0) \\
\hline \multicolumn{4}{|l|}{ Race/ethnicity (\%) } \\
\hline Non-Hispanic White & 20.0 & 20.2 & 20.1 \\
\hline Non-Hispanic Black & 6.6 & 7.5 & 7.1 \\
\hline Mexican American & 49.3 & 47.8 & 48.5 \\
\hline Other Race & 19.8 & 20.0 & 19.9 \\
\hline Other Hispanic & 4.3 & 4.5 & 4.4 \\
\hline $\begin{array}{l}\text { Body mass index, } \mathrm{kg} / \mathrm{m}^{2} \text { [median } \\
(\mathrm{IQR}) \text { ] }\end{array}$ & $27.5(6.6)$ & $27.8(9.0)$ & $27.7(7.7)$ \\
\hline $\begin{array}{l}\text { Low-density lipoprotein } \\
\text { cholesterol, mg/dL [median } \\
\text { (IOR)] }\end{array}$ & $117.0(46.0)$ & $114.0(47.0)$ & $115.0(47.0)$ \\
\hline Diabetes (\%) & 15.3 & 13.5 & 14.3 \\
\hline \multicolumn{4}{|l|}{ Smoking status (\%) } \\
\hline Current smoker & 25.8 & 18.0 & 21.7 \\
\hline Former smoker & 31.8 & 20.1 & 25.7 \\
\hline Non smoker & 42.4 & 61.9 & 52.6 \\
\hline
\end{tabular}

$I Q R$, interquartile range.

linked with $16 \%$ of stroke risk reduction in females $(95 \% \mathrm{Cl}$ : 0.01-0.28).

Our findings of the overall association between CRP level and risk of stroke are in line with several previous reports. In a large US case-cohort study, the highest CRP category was associated with an increased risk of stroke by a 1.87 -fold. ${ }^{4} \mathrm{~A}$ similar association was noted in a US cohort study, with a 3.08-fold of stroke occurrence in elevated CRP group. ${ }^{5}$ However, the correlation was not significant in a prospective study, which was conducted in the Netherlands. ${ }^{3}$ It is still uncertain whether the differences of the association are due to geography, genetic or hormone level, which need further explorations. It is noteworthy that increased CRP was a significant risk factor of stroke among women rather than men, which was confirmed in our multivariate logistic analysis results and further supported by population attributable fractions analysis results. Our findings are consistent with several prior studies. The Framingham study observed that the highest quartile CRP level was linked with significant increase of ischemic stroke or transient ischemic attack among females (risk ratio $=2.1 ; 95 \% \mathrm{Cl}: 1.19-3.83$ ), whereas the association disappeared among males (risk ratio $=1.6 ; 95 \% \mathrm{Cl}: 0.87-3.13$ ). ${ }^{6}$ In another cohort study, the risks of cardiovascular diseases associated with CRP concentration were greater for females than for males (risk ratio: 1.60 vs. 1.07). ${ }^{7}$ A similar pattern was also confirmed by comparison of the association strengths of two cohort studies that were conducted in females and males, respectively (risk ra- tio: 5.5 vs. 2.8). ${ }^{8,9}$ While, a Chinese study revealed that gender modified the association in an opposite way. They observed elevated CRP had significant effect on male instead of females subjects. ${ }^{10}$ Inconsistent findings of the gender differences may be partly due to hormone and/or genetic distinctions among women and men, although the underlying mechanisms are still unclear and require deeper investigations.

\section{References}

1. Cao JJ, Arnold AM, Manolio TA, Polak JF, Psaty BM, Hirsch CH, et al. Association of carotid artery intima-media thickness, plaques, and C-reactive protein with future cardiovascular disease and all-cause mortality: the Cardiovascular Health Study. Circulation 2007;116:32-38.

2. Coffman $E_{1}$ Richmond-Bryant J. Multiple biomarker models for improved risk estimation of specific cardiovascular diseases related to metabolic syndrome: a cross-sectional study. Popul Health Metr 2015;13:7.

3. Bos MJ, Schipper CM, Koudstaal PJ, Witteman JC, Hofman A, Breteler MM. High serum C-reactive protein level is not an independent predictor for stroke: the Rotterdam Study. Circulation 2006;114:1591-1598.

4. Ballantyne CM, Hoogeveen RC, Bang $H$, Coresh J, Folsom AR, Chambless $L E$, et al. Lipoprotein-associated phospholipase $A 2$, high-sensitivity $\mathrm{C}$-reactive protein, and risk for incident ischemic stroke in middle-aged men and women in the Atherosclerosis Risk in Communities (ARIC) study. Arch Intern Med 2005;165:2479-2484.

5. Tzoulaki I, Murray GD, Lee AJ, Rumley A, Lowe GD, Fowkes FG. Relative value of inflammatory, hemostatic, and rheological factors for incident myocardial infarction and stroke: the Edinburgh Artery Study. Circulation 2007;115:2119-2127.

6. Rost NS, Wolf PA, Kase CS, Kelly-Hayes M, Silbershatz H, Massaro JM, et al. Plasma concentration of C-reactive protein and risk of ischemic stroke and transient ischemic attack: the Framingham study. Stroke 2001;32:2575-2579.

7. Tracy RP, Lemaitre RN, Psaty BM, Ives DG, Evans RW, Cushman $M$, et al. Relationship of C-reactive protein to risk of cardiovascular disease in the elderly. Results from the Cardiovascular Health Study and the Rural Health Promotion Project. Arterioscler Thromb Vasc Biol 1997;17:1121-1127.

8. Ridker PM, Buring JE, Shih J, Matias M, Hennekens CH. Prospective study of $\mathrm{C}$-reactive protein and the risk of future cardiovascular events among apparently healthy women. Circulation 1998;98:731-733.

9. Ridker PM, Cushman M, Stampfer MJ, Tracy RP, Hennekens $\mathrm{CH}$. Inflammation, aspirin, and the risk of cardiovascular dis- 
ease in apparently healthy men. N Engl J Med 1997;336:973979.

10. Liu Y, Wang J, Zhang L, Wang C, Wu J, Zhou Y, et al. Relationship between $\mathrm{C}$-reactive protein and stroke: a large prospective community based study. PLoS One 2014;9:e107017.
Correspondence: Yang Peng

Centre for Chronic Disease, School of Medicine, University of Queensland, 280 Herston Road, Herston 4029, Australia

Tel: +61-7-3346-5149, Fax: +61-7-3346-5149

E-mail: yang.peng@uq.net.au

Received: May 22, 2016

Revised: May 23, 2016

Accepted: May 23, 2016

We gratefully acknowledge the staff at the National Center for Health

Statistics who were responsible for planning and conducting the National Health and Nutrition Examination Survey (NHANES).

This work was supported by National Health and Medical Research Council of Australia (APP1042343).

The authors have no financial conflicts of interest. 